\title{
EPSL
}

Earth and Planetary Science Letters 133 (1995) 1-17

\section{A laboratory investigation of effects of trench migration on the descent of subducted slabs}

\author{
Ross W. Griffiths, Ronald I. Hackney ${ }^{1}$, Rob D. van der Hilst \\ Research School of Earth Sciences, Australian National University, Canberra, A.C.T. 0200, Australia
}

Accepted after revison 21 February 1995

\begin{abstract}
A laboratory investigation of viscous slabs subducted from a migrating trench reveals a range of possible behaviours. The slab dip in a uniform mantle is found to be steady or oscillatory, depending on the rates of descent and trench migration. In addition, density and viscosity interfaces are used to model the increased resistance to sinking of stiff slabs through the seismic discontinuity at a depth of about $660 \mathrm{~km}$ in Earth's mantle. If the slab is denser than the lower layer and its dip in the upper layer is steady, it can continue to descend through the lower layer in a tabular form and in either a steady or oscillatory manner, or it can be laid horizontally on the interface for a distance before descending in a chain of diapirs resulting from gravitational instability at the interface. If the slab dip in the upper layer is unstable, the slab sinks into the lower layer in a chain of large diapirs at a spacing determined by the frequency of oscillations set by instability of the slab within the upper layer. The style of penetration depends on the trench migration speed and the ratio of sinking velocities in the two layers. Estimates for mantle slabs indicate that they may range across the major regime transitions. The experimental system provides a gross simplification of mantle conditions but the results are a testimony to the possibility of a range of complex behaviour of subducted lithosphere. They also indicate that the relationship between the structural features in the lower mantle revealed by seismic imaging and present-day tectonic processes at the surface may not be obvious. Tomographic images of western Pacific subduction zones and data for the migration rates of associated trenches suggest a dependence of slab behaviour on migration rate similar to that seen in the experiments.
\end{abstract}

\section{Introduction}

Seismic imaging has not yet provided unequivocal information on the fate of subducted lithosphere. A number of workers have found evidence for direct penetration of slabs through the transition zone and into the lower mantle [1-8]. Others have argued that slabs are deflected on encountering the phase bound-

\footnotetext{
${ }^{1}$ Now at: Institute of Geophysics, Victoria University of Wellington, New Zealand
}

ary at $660 \mathrm{~km}$ and are laid horizontally at that depth [9-12]. For detailed discussions of the seismic evidence pertinent to the fate of subducted lithosphere see [13-17]. Regional tomographic studies of mantle structure beneath western Pacific island arcs [18-22] indicate that, in places, slabs have penetrated into the lower mantle but in others appear to be blocked and spreading above the phase boundary. Van der Hilst and Seno [23] point out that tomographic images are only a snapshot in time and that slab morphology and mass flux into the lower mantle may be a transient phenomenon. If this is the case a presence 
of subhorizontal sections of slabs need not indicate a blocking of mass flux from the upper to the lower mantle but merely a temporary and local distortion of the slab morphology.

Other aspects of slab morphology which are not entirely understood are the angle of dip and shape of the slab within the upper mantle. Earthquake foci reveal a wide range of slab dips from vertical to subhorizontal, as well as both linear and buckled Wadati-Benioff zones [9-11,23-27]. The morphology of the slab in the upper mantle may be influenced by many factors [28], including the age and thickness of the lithosphere at the trench [26,29-31], the relative plate motions [32,33], subduction history [34] and the presence of the mid-mantle transition zone. However, it is not clear which factors are dominant or, in particular, whether the dip would be constant (stable) for given plate velocities.

Near the transition zone a range of possible slab behaviours not unlike that inferred from the seismic data is predicted using numerical models. Two-dimensional convection computations $[35,36]$ indicate little impedance to transport across a mid-mantle interface if the compositional density difference is less than $2 \%$ and the magnitude of the negative Clapeyron slope $\gamma$ for the phase change from spinel to perovskite and magnesiowüstite is not too large, but significant impedance to transport for moderate Clapeyron slopes $(-6<\gamma<-2 \mathrm{MPa} / \mathrm{K})$ and a density difference between 2 and 5\%. Other two-dimensional models [37-40] predict that mass flux to the lower mantle will be episodic when $\gamma \approx-4$ $\mathrm{MPa} / \mathrm{K}$, which is at the high end of the spectrum of published values of $\gamma$. For larger or smaller values of $\gamma$ these models predict, respectively, two-layer convection or only minor effects of the phase boundary. Intermittent penetration is also an obvious feature of the flow in three-dimensional models [41,42], wherein downwelling linear sheets in the upper mantle tend to accumulate buoyancy above the $660 \mathrm{~km}$ discontinuity until they eventually penetrate and produce cylindrical downwellings in the lower mantle. The above numerical models, however, were limited to a constant viscosity, precluding any effects of a viscosity jump between the slab and its surroundings or between the upper and lower mantle. Neither did they include stiff, moving lithospheric plates at the surface, with their associated ridge and trench dy- namics, which are such a characteristic feature of the mantle.

Some complementary knowledge of the effects of a density or viscosity interface is available from laboratory experiments. Kincaid and Olson [43] described three subduction regimes observed in experiments with slabs of very high viscosity sinking into less viscous surroundings. Slab penetration of a density interface depended on the angle of dip of the slab and, more importantly, on the ratio of density differences. The boundary condition at the 'ridge' end of the surface plate determined the migration of the trench: a fixed ridge (or more resistance to slab penetration at depth in the case of a free ridge) resulted in faster trench migration. As a corollary, faster trench migration resulted in a smaller angle of dip. Griffiths and Turner $[44,45]$ examined the case of a vertically falling viscous sheet impinging on density or viscosity interfaces between two viscous layers and established that a folding or buckling instability occurred when the viscosity contrast between slab and mantle was large and the depth of the upper layer exceeded a critical value (approximately 3 times the thickness of the sheet). A buckling slab can spread on the interface even if the slab is denser than the lower layer, or it can produce broad complex downwellings in the lower layer. Buckling of inclined slabs penetrating into a lower mantle 10 to 30 times more viscous than the upper mantle was also found in numerical experiments $[33,46,47]$.

Laboratory experiments cannot include the effects of a phase change with non-zero Clapeyron slope. However, the effects of an interface or phase boundary are primarily through a change in either the slab buoyancy or the resistance to the descending motion, and hence to a change in sinking velocity. Whether this change in sinking velocity is due to changed viscous stresses, a permanent change in slab buoyancy, or a local, temporary change in buoyancy produced by deflection of the phase boundary is not of primary importance in determining the slab motion in the upper mantle.

In this paper we describe the results of experiments that examine the behaviour of viscous sheets (slabs) falling through a layer of uniform viscous material or impinging on discontinuities of density or viscosity. These experiments are an extension of the earlier work of Griffiths and Turner $[44,45]$, but are 
designed to explore the effects of trench migration on slab dip and on the fate of the subducted slabs. They are also seen as complementary to the experiments of Kincaid and Olson [43] since we wish to explore a wider range of parameter values than can practically be achieved when using surface plates and imposing conditions on the plate boundaries. We also make comparisons with recent tomographic images of the mantle beneath the western Pacific subduction zones [19,20,22]. We reinforce the point that these images are only snapshots of time-dependent structure and that they must be interpreted in the context of dynamic models and the full range of behaviour that may be possible.

\section{Flow parameters}

In order to investigate effects of trench migration on subducted slabs we selected some of the most significant features of mantle flow and designed a relatively simple laboratory experiment. We retain a thin and more viscous lithospheric slab falling under its own buoyancy through less viscous surroundings. Of most interest for the present study are, first, the slab descent through a uniform layer and, second, its interaction with an interface at which the slab experiences a decreased driving force or an increased resistance to further descent. To investigate the latter we use two layers of different density or viscosity, with the slab always more dense than the lower layer.

There are three velocities inherent in mantle flow (Fig. 1): the subduction velocity $u_{\mathrm{P}}$ (the horizontal convergent velocity of the subducting plate relative to the trench), the velocity $u_{\mathrm{m}}$ of trench migration relative to Earth or the bulk of the underlying mantle

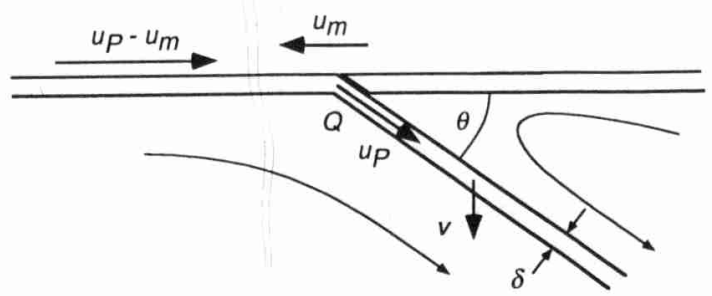

Fig. 1. Sketch of plate subduction defining variables, including three velocities describing the flow relative to Earth. (taken as positive towards the subducting plate), and a vertical sinking velocity $\nu$ of the slab determined by a balance between slab buoyancy and viscous drag. The velocity of the surface plate relative to Earth in this simple rectilinear view is $u_{\mathrm{P}}-u_{\mathrm{m}}$. The subduction velocity characterises the motion of slab material along the plane of the slab, whereas the sinking velocity is the rate of change of slab location in the vertical. Thus gently dipping slabs may glide along their quasi-horizontal plane at a velocity $u_{\mathrm{p}}>\nu$ determined by the plate speed, whereas the dip is determined, at least in part, by the ratio of sinking velocity $\nu$ and migration velocity $u_{m}$. The three velocities are not independent in the mantle since the buoyancy of the slab is largely responsible for both the subduction velocity $u_{P}[15]$ as well as the sinking velocity, and there will also be complex interaction between trench migration, sinking speed and subduction rate. The experiments of Kincaid and Olson [43] represent an attempt to model these interactions. However, it is instructive to vary parameters independently. In the experiments reported here $u_{\mathrm{m}}$ and $\nu$ are independent, whereas $u_{\mathrm{p}}$ (and slab thickness) is internally determined by $u_{\mathrm{m}}, \nu$ and source flowrate.

The sinking velocity $\nu$ relative to the mantle can be expressed in an approximate way by assuming that slabs are viscous and much longer than their thickness. The buoyancy force per unit length and width of slab is $g\left(\rho_{\mathrm{s}}-\rho_{i}\right) \delta$, where $g$ is the acceleration due to gravity, $i=1$ or 2 depending on which layer the slab is in and $\delta$ is the slab thickness, while the viscous drag is proportional to $\delta / \eta_{i}$. The balance results in the usual Stokes scaling for sinking velocity

$\nu_{i}=k g\left(\rho_{\mathrm{s}}-\rho_{i}\right) \delta^{2} / \eta_{i}$

where $k$ is an unknown numerical constant. An identical argument has been used to describe the ascent of hot, relatively low viscosity plumes through the mantle and was rigorously tested in experiments [48]. Although slabs are more viscous than their surroundings it is difficult to escape a similar scaling. Our experiments provide an approximate test of this approach and an empirical value for $k$ is found.

The effects on slab motion of the interface between the two layers is described by two dimensionless parameters, the ratio $\beta$ of density differences 
$\left[\beta=\left(\rho_{\mathrm{s}}-\rho_{2}\right) /\left(\rho_{\mathrm{s}}-\rho_{1}\right)\right]$ [43-45] and the ratio $\eta_{2} / \eta_{1}$ of viscosities in the two layers. Here $\rho_{\mathrm{s}}$ is the slab density and $\rho_{1}$ and $\rho_{2}$ are the densities of the upper and lower layers respectively. When $\beta=0$, the lower layer has the same density as the descending sheet and there is no buoyancy force available to drive motion through the lower layer. A negative value of $\beta$ implies the slab is less dense than the lower layer. When $\beta=1$ there is no change in slab buoyancy as it passes through the interface.

A useful measure of the overall effect of the interface is the ratio of sinking velocities for the slab in the upper and lower layers. From (1) this ratio is

$\nu_{1} / \nu_{2}=\beta^{-1}\left(\eta_{2} / \eta_{1}\right)$

When the layer properties provide an interface with great resistance to penetration, or the lower layer density approaches that of the slab, the velocity ratio is large.

\section{Slab dip and migration velocity}

In the absence of trench migration slabs can descend at angles of less than $90^{\circ}$ as a result of asymmetry in the surface velocity boundary conditions imposed by the over-riding and subducting plates, which leads to reduced pressure in the wedge beneath the over-riding plate [32]. However, the dip will also be influenced by trench migration [33,34]. Here we disregard any effects the surface plates may have on the underlying flow and concentrate on the effects of trench migration coupled with flow driven by the sinking part of the slab. The slab dip is then $90^{\circ}$ for a stationary trench and tends to be smaller for larger migration velocities.

If we assume the slab to be very thin compared to the depth of the upper mantle and the rheology is adequately represented by an effective Newtonian viscosity, a simple relationship between migration velocity and slab dip follows from the buoyancydriven descent of slab material. In a reference frame fixed in Earth, and if we assume that the motion of the slab is uniform, or stable, so that each section of the slab experiences the same drag and the slab remains of uniform thickness, each element of the slab descends vertically and at the same speed. Disregarding any weak dependence of the constant $k$ in (1) on slab dip we have a tabular structure inclined to the horizontal at an angle $\theta$, where

$\tan \theta=\nu_{1} / u_{\mathrm{m}}$

We do not present a stability analysis here since the problem is complex, involving inclined slabs of finite length, width and thickness, and finite mantle layer depths. Instead we report our experimental results which reveal that the slab motion is stable, or steady, under only a limited range of conditions. Beyond these conditions (3) has little meaning.

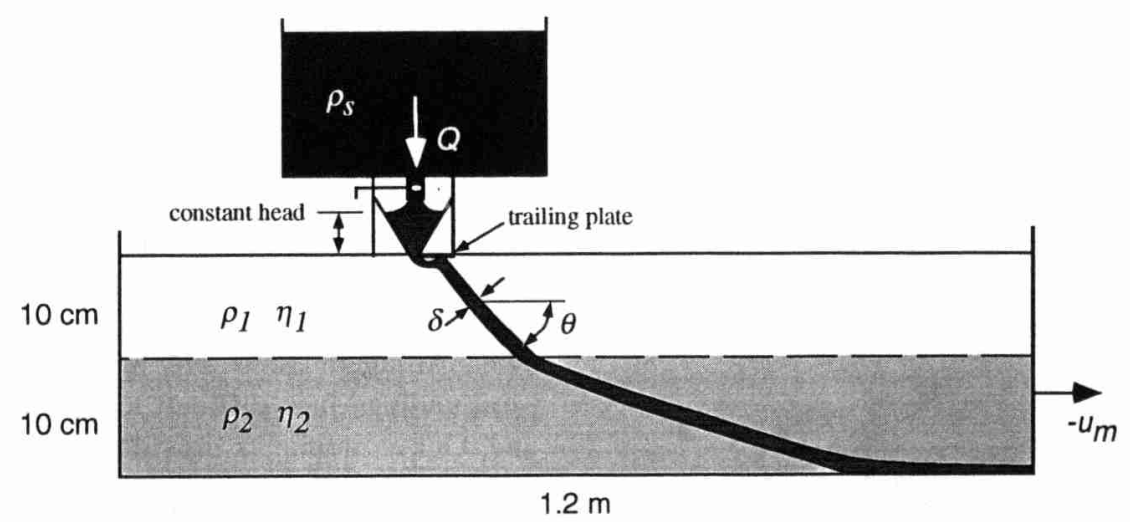

Fig. 2. Sketch of the experimental apparatus. The larger reservoir suspended above the tank supplies slab fluid to a smaller V-shaped feeder reservoir. An outlet pipe on the supply reservoir is adjusted to maintain a constant fluid head in the feeder reservoir, thus giving a constant fluid flux through the slit. The tank containing the 'mantle' rests on a platform that runs on rails and is pulled by a motor and pulley. 


\section{The experiments}

The apparatus and techniques used here are similar to those used in the earlier work of Griffiths and
Turner $[44,45]$. However, in order to include trench migration a $1.1 \mathrm{~m}$ long tank was used with a mechanical towing mechanism. The subducted slab was produced from a thin slit, $10 \mathrm{~cm}$ wide and adjustable

Table 1

Parameter values for the experiments from which data are taken and guide to illustrative photographs. Values for slab dip and normalised migration velocity are only approximate for cases in which the slab dip was oscillatory. For comparison subduction velocities $u_{\mathrm{P}}$ along the slab measured at mid-depth in the upper layer of stable cases were between 2.0 and $2.8 \mathrm{~mm} / \mathrm{s}$ (except in runs 14 and 18 , where upper layer viscosity was relatively small). Densities given are accurate to $\pm 0.1 \%, \beta$ to $\pm 5 \%$, viscosities to $\pm 2 \%, u_{\mathrm{m}}$ to better than $0.1 \mathrm{~mm} / \mathrm{s}$, slab thickness to $\pm 10 \%$, scaled migration speed to $\pm 20 \%$, and dip to $\pm 2^{\circ}$

\begin{tabular}{|c|c|c|c|c|c|c|c|c|c|}
\hline Exp\# & $\rho_{s} / \rho_{I}$ & $\beta$ & $\eta_{s} / \eta_{l}$ & $\eta_{2} / \eta_{1}$ & $v_{1} / v_{2}$ & $\begin{array}{c}u_{m} \\
(\mathrm{~mm} / \mathrm{s})\end{array}$ & $\frac{u_{m} \eta_{l}}{g\left(\rho_{s}-\rho_{l}\right) \delta^{2}}$ & $\begin{array}{c}\theta_{1} \\
(\mathrm{deg})\end{array}$ & $\begin{array}{l}\text { photo' } \\
\text { (figure) }\end{array}$ \\
\hline 1 & 1.042 & - & 8.0 & - & 1 layer & $0,2.0$ & $0,0.04$ & 60 & $3 a$ \\
\hline 3.1 & 1.026 & - & 8.0 & - & 1 layer & 1.9 & 0.177 & 40 & \\
\hline 3.2 & 1.026 & - & 8.0 & - & 1 layer & 2.4 & 0.176 & 39 & \\
\hline 3.3 & 1.026 & - & 8.0 & - & 1 layer & 2.9 & - & $\therefore$ & \\
\hline 4.1 & 1.024 & - & 8.2 & - & 1 layer & 1.9 & 0.043 & 58 & $3 b$ \\
\hline 4.2 & 1.024 & - & 8.2 & - & 1 layer & 0.9 & 0.082 & 58 & \\
\hline 4.3 & 1.024 & - & 8.2 & - & 1 layer & 0.9 & 0.065 & 56 & \\
\hline 6.1 & 1.024 & - & 7.7 & - & 1 layer & 1.9 & 0.064 & 60 & \\
\hline 6.2 & 1.024 & - & 7.7 & - & 1 layer & 1.9 & 0.059 & 65 & \\
\hline 7.1 & 1.025 & - & 8.0 & - & 1 layer & 3.6 & 0.29 & $27-57$ & $3 c$ \\
\hline 7.2 & 1.025 & - & 8.0 & - & 1 layer & 2.5 & 0.117 & 51 & \\
\hline 8.1 & 1.024 & 0.50 & 7.6 & 2.8 & 5.65 & 1.8 & 0.104 & 53 & \\
\hline 8.2 & 1.024 & 0.50 & 7.6 & 2.8 & 5.65 & 3.0 & 0.107 & 51 & $7 c$ \\
\hline 8.3 & 1.024 & 0.50 & 7.6 & 2.8 & 5.65 & 3.8 & 0.221 & $28-55$ & \\
\hline 9.1 & 1.025 & 0.75 & 7.3 & 1.5 & 1.94 & 1.1 & 0.039 & 61 & $7 a$ \\
\hline 9.2 & 1.025 & 0.75 & 7.3 & 1.5 & 1.94 & 2.9 & 0.166 & $41-59$ & \\
\hline 9.3 & 1.025 & 0.75 & 7.3 & 1.5 & 1.94 & 3.9 & 0.270 & $24-52$ & \\
\hline 9.4 & 1.025 & 0.75 & 7.3 & 1.5 & 1.94 & 2.0 & 0.062 & 54 & \\
\hline 10.1 & 1.025 & 0.75 & 7.3 & 1.5 & 1.94 & 3.0 & 0.144 & $33-55$ & \\
\hline 10.2 & 1.025 & 0.75 & 7.3 & 1.5 & 1.94 & 1.8 & 0.055 & 54 & \\
\hline 11.1 & 1.023 & 0.30 & 7.1 & 3.7 & 12.3 & 1.1 & 0.036 & 62 & \\
\hline 11.2 & 1.023 & 0.30 & 7.1 & 3.7 & 12.3 & 2.0 & 0.058 & 50 & \\
\hline 11.3 & 1.023 & 0.30 & 7.1 & 3.7 & 12.3 & 2.9 & 0.128 & $33-56$ & \\
\hline 12.1 & 1.024 & 0.73 & 6.5 & 1.6 & 2.24 & 1.9 & 0.061 & 57 & $7 b$ \\
\hline 12.2 & 1.024 & 0.73 & 6.5 & 1.6 & 2.24 & 3.7 & 0.219 & $35-60$ & $7 e$ \\
\hline 12.3 & 1.024 & 0.73 & 6.5 & 1.6 & 2.24 & 1.1 & 0.040 & 66 & \\
\hline 13.1 & 1.022 & 0.18 & 7.1 & 4.9 & 27.1 & 3.8 & 0.237 & $35-65$ & $7 f$ \\
\hline 13.2 & 1.022 & 0.18 & 7.1 & 4.9 & 27.1 & 2.5 & 0.096 & 56 & $7 d$ \\
\hline 13.3 & 1.022 & 0.18 & 7.1 & 4.9 & 27.1 & 1.2 & 0.046 & 67 & \\
\hline 14.1 & 1.021 & 0.93 & 402.6 & 73.9 & 79.5 & 3.9 & 0.004 & 65 & \\
\hline 14.2 & 1.021 & 0.93 & 402.6 & 73.9 & 79.5 & 6.6 & 0.007 & 57 & \\
\hline 14.3 & 1.021 & 0.93 & 402.6 & 73.9 & 79.5 & 8.4 & 0.009 & $40-73$ & \\
\hline 16.1 & 1.046 & - & 28.46 & - & 1 layer & 3.8 & 0.043 & & \\
\hline 16.2 & 1.046 & - & 28.46 & - & 1 layer & 3.8 & 0.043 & & \\
\hline 16.3 & 1.046 & - & 28.46 & - & 1 layer & 8.4 & 0.094 & & \\
\hline 17.1 & 1.023 & - & 5.44 & - & 1 layer & 3.8 & 0.186 & & \\
\hline 17.2 & 1.023 & - & 5.44 & - & 1 layer & 5.6 & 0.274 & & \\
\hline 17.3 & 1.023 & - & 5.44 & $31-$ & 1 layer & 4.8 & 0.235 & & \\
\hline 17.4 & 1.023 & - & 5.44 & - & 1 layer & 6.4 & 0.313 & & \\
\hline 17.5 & 1.023 & - & 5.44 & - & 1 layer & 4.4 & 0.215 & & \\
\hline 17.6 & 1.023 & - & 5.44 & - & 1 layer & 8.4 & 0.411 & & \\
\hline 18.1 & 1.042 & - & 148.1 & - & 1 layer & 1.7 & 0.046 & & \\
\hline 18.2 & 1.042 & - & 129.2 & - & 1 layer & 2.4 & 0.066 & & \\
\hline 18.3 & 1.042 & - & 92.01 & - & 1 layer & 0.9 & 0.024 & & \\
\hline
\end{tabular}


in thickness, connected to supply reservoirs suspended above the tank (Fig. 2). The tank was three times wider $(30 \mathrm{~cm})$ than the slit, a compromise which minimised the side wall influences while providing for clearer visualization of the flow. The outlet of the source was positioned slightly below the free surface of the experimental mantle. A horizontal perspex plate was attached to the trailing side of the slit source in order to prevent slab material contacting the free surface behind the source. This plate also provides boundary conditions more similar to those in the mantle due to the presence of an over-riding plate. The slit mechanism and source reservoirs were fixed in the laboratory and migration was achieved by mechanically towing the whole tank past the slit. Photographs and video records were taken with cameras stationary relative to the source.

The model slab consisted of either pure 'golden syrup' $\left(\rho_{\mathrm{s}}=1.45 \times 10^{3} \mathrm{~kg} \mathrm{~m}^{-3}, \nu_{\mathrm{s}}=1.5 \times 10^{-2}\right.$ $\mathrm{m}^{2} \mathrm{~s}^{-1}$ ) or clear glucose syrup (dyed to make it visible). The 'mantle' was a mixture of glucose syrup and water. The tank was filled with two layers of approximately equal depth $(H \approx 8-10 \mathrm{~cm})$. Variations in the density and viscosity of the mantle layers were in most cases achieved simply by varying the water content of the mixture. In order to form a large step in viscosity without a significant density difference an upper layer of glucose syrup and potassium carbonate solution was used [44]. We chose to run only isothermal experiments because the Peclet number $u_{\mathrm{p}} \delta / \kappa>10^{3}$ for mantle slabs and the distance to the $670 \mathrm{~km}$ discontinuity is less than 10 slab thicknesses. Therefore heat conduction can affect only very small degrees of warming. As a practicality, use of compositionally determined rheology and buoyancy admitted small flow velocities and slab thicknesses.

The conditions for the experiments illustrated in this paper are shown in Table 1 . The sinking velocity scale $g\left(\rho_{\mathrm{s}}-\rho_{i}\right) \delta^{2} / \eta_{i}$, along with the ratios $\beta$ and
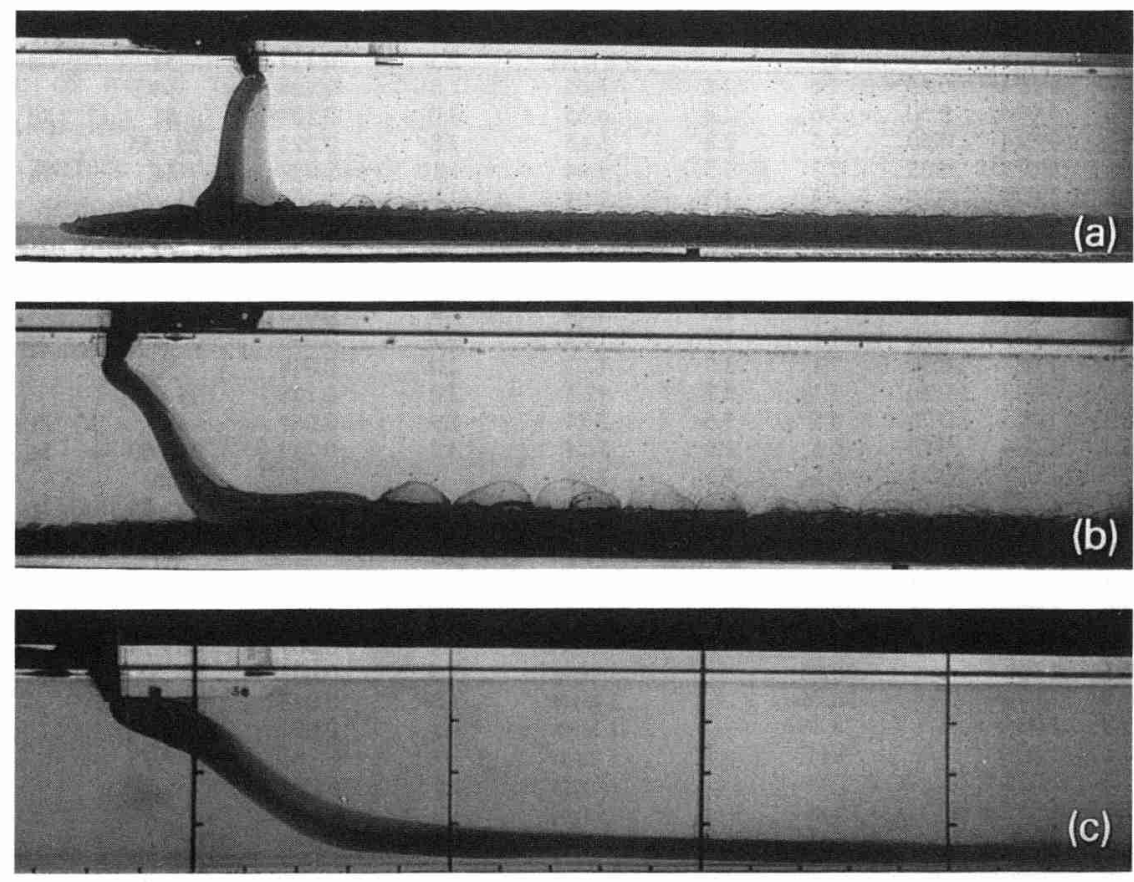

Fig. 3. Photographs of the stability regimes for the single-layer experiments. Trench migration is to the left. (a) No source migration gives near-vertical slab descent and folding occurs near the tank base (a layer of slab material on the base is left from an earlier part of the experiment in which the trench moved to the left). (b) Stable flow with a constant dip (instability along the base is simply due to some ambient less dense 'mantle' trapped againt the base). (c) A snapshot of an unstable flow with oscillating dip (taken close to a time of minimum dip). Vertical scale marks are $2 \mathrm{~cm}$ apart and their horizontal spacing is $10 \mathrm{~cm}$. 
$\eta_{2} / \eta_{1}$, were varied by changing layer densities and viscosities. The subduction velocity $u_{\mathrm{P}}$ (in this case the down-slab velocity of source material after a flow adjustment near the slit) could also be varied by changing the thickness of the source slit or the gravitational pressure head forcing flow from the source. However, here we report results from only those experiments using a fixed slit thickness $(2 \mathrm{~mm})$ and source flowrate since this reduces the number of variables. Values of the subduction velocity $u_{\mathrm{p}}$ in these cases varied little, whereas the migration speeds used covered the range $0.3<u_{\mathrm{p}} / u_{\mathrm{m}}<3$. In order to compute the slab sinking velocity and normalise the source migration velocity we used the measured slab thickness at mid-depth in the upper layer.

\section{Results}

Although our real interest is in the behaviour of slabs in the two-layer system, it is necessary to first understand the flow when a relatively viscous slab is falling through a single homogeneous layer.

\subsection{Single layer}

Experiments with slabs descending through a single layer revealed a sequence of at least four different flow regimes, depending on migration velocity. The various slab configurations identified are illustrated by the photographs in Fig. 3 .

For a stationary source the slab descended almost vertically through the upper part of the layer, but buckled near the base, laying down folds on the slab material ponded at the base (Fig. 3a). This is the folding instability discussed by Griffiths and Turner [44]. For non-zero but small migration speeds $\left(u_{\mathrm{m}} \eta_{1} / g\left(\rho_{\mathrm{s}}-\rho 1\right) \delta^{2}<0.12 \pm 0.02\right)$ the slab motion became completely steady (in the reference frame moving with the source) with a well-defined dip (Fig. 3b). We measured the dip at mid-depth in the layer. The flow was stable, the compressive stresses parallel with the plane of the slab being too small to cause buckling. Steady slabs (with a viscosity 5 to 150 times that of the surroundings) were obtained with dips $\theta$ between $70^{\circ}$ and approximately $45^{\circ}$. (The dependence of dip on migration speed is discussed in Section 6.1.) Under these conditions we

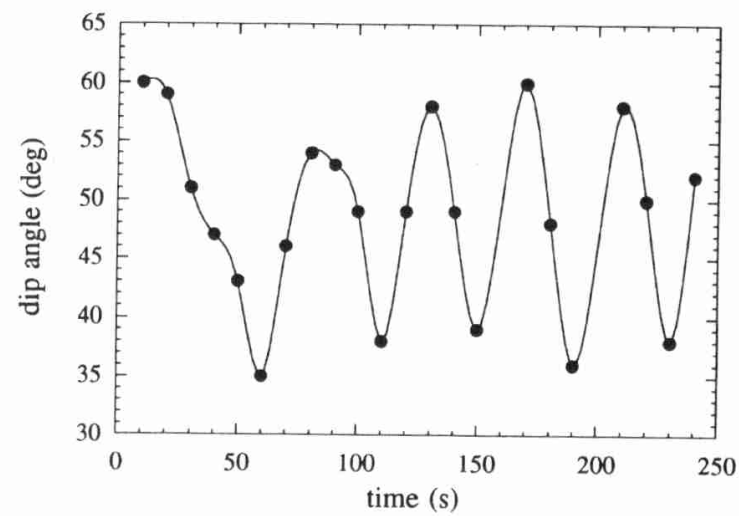

Fig. 4. Slab dip as a function of time illustrating the periodicity when the slab is unstable in the upper layer of a two-layer 'mantle' (run 12.2 in Table 1). Measurements were taken at selected phases of the oscillation from video records (which show that variations were smooth and justify the smooth curves shown). The period of $40 \mathrm{~s}$ in this run is equal to $6.8 \mathrm{H} / \nu_{1}$.

also noted that the slab tended to become attached to the trailing (over-riding) plate for some distance before sinking, the length of attachment being greater for greater migration speeds.

At normalised migration speeds greater than the critical value of 0.12 the inclined slab underwent a gravitational instability over most of its height. Near marginally unstable conditions small oscillations appeared on the deepest part of the inclined viscous sheet, but for larger $u_{\mathrm{m}}$ the whole of the descending part of the slab became involved and the amplitude of oscillation increased (Fig. 3c). The oscillatory nature of the flow appeared as a periodic variation in dip $\theta$. Dips measured in an example of oscillatory flow are plotted in Fig. 4. Oscillation periods were approximately $7 H / \nu_{1}$, where $H / \nu_{1}$ is a fundamental timescale for the flow. However, further investigation and analysis of the instability is required.

In addition, a sequence of runs with a fixed migration velocity showed that the motion could change from steady to unstable when the density contrast between slab and mantle was decreased. A smaller sinking velocity leads to a smaller dip. Likewise, increasing the width of the source tended to make the slab thicker, sink faster, and to be more stable. Thus stability depends primarily on the slab dip. Changing the slit width, however, also altered the subduction (entrance) velocity and it became 
difficult to keep track of the separate effects of slab thickness $\delta$ and subduction velocity $u_{\mathrm{p}}$. We therefore restrict our discussion to results from a fixed source width of $2 \mathrm{~mm}$ and concentrate on the effects of varying sinking velocity, density difference and migration speed. Stability was also influenced by the 'mantle' viscosity through its effect on the sinking velocity (1) and the dip angle (3). On the other hand, there was no evidence that stability depended on slab 'stiffness' (the viscosity contrast between the slab and the 'mantle') over the accessible range (Fig. 5).

\subsection{Two layers}

In two-layer experiments we concentrated on non-zero migration velocities (see [44] for that case) and on migration speeds small enough for there to be a slab-like structure in the upper layer. Even so, many different behaviours were identified, and these were classified into four primary flow regimes. The regimes are summarised in Fig. 6 as a function of the migration speed and velocity ratio $\nu_{1} / \nu_{2}$. Examples of the resulting slab morphologies are shown in Fig. 7. Naturally, as with seismic tomographic images of the mantle snapshots of unsteady laboratory flows do not uniquely indicate the nature of the motion. For this we must draw on the information available from

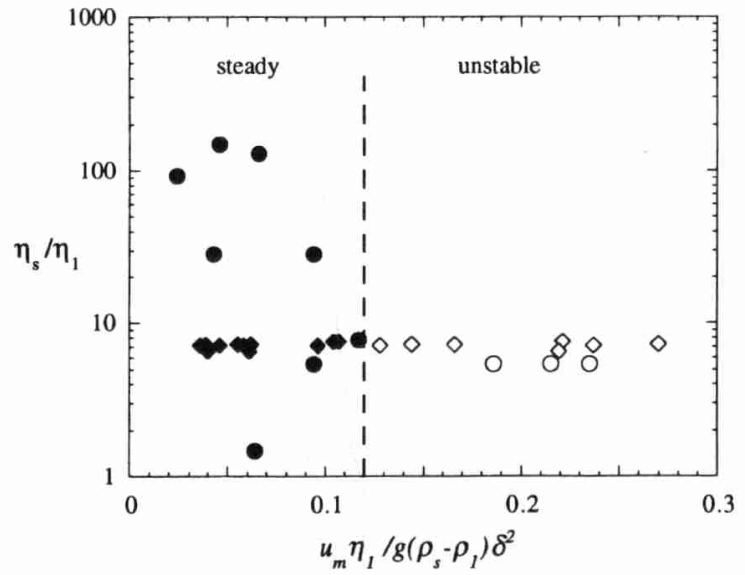

Fig. 5. The dependence of stability on slab 'stiffness'. $\bigcirc$ and - single-layer runs; $\diamond$ and $\bullet=$ two-layer runs; filled symbols = steady stable motion; empty symbols = unsteady flow in the upper layer. These data are for runs with a constant slit width of 2 $\mathrm{mm}$.

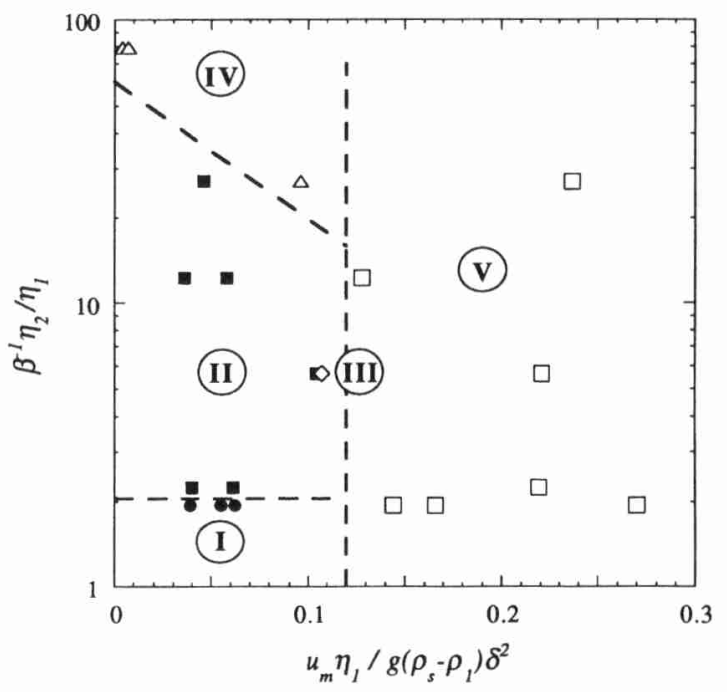

Fig. 6. Summary of the primary penetration styles observed in two-layer experiments as a function of the ratio of sinking velocities and normalised trench migration speed. Approximate boundaries between regimes are shown. Data points have uncertainties of $20 \%$ on the abcissa and $10 \%$ in the ordinate. Flow regimes: $\mathrm{I}=$ steady flow with the interface having no effect (Fig. 7a); $\mathrm{II}=$ steady flow with a decrease in dip angle across the interface (Fig. 7b); III = steady motion in the top layer, but with angle change across the interface so large that the slab is unstable in the lower layer (Fig. 7c); IV = steady motion in the top layer, with diapiric slab descent in the lower layer after emplacement of a horizontal layer of slab at the interface (Fig. 7d); V = oscillatory motion in the top layer (not related to the interface), forcing periodic penetration into the lower layer at the same frequency (Fig. 7e and f).

velocity fields, Lagragian tracers and temporal evolution of the flow.

In order of increasing velocity ratio and increasing migration speed the first regime is that in which the slab was steady everywhere and simply penetrated directly through both layers, the interface having no significant effect (regime I, Fig. 7a) (i.e., the descent of the slab in the two-layer system was as if there were a single layer of the full depth of the tank). When the source was stationary, the slab again folded at the base of the tank. For non-zero migration speeds flow was steady (no folding) with constant dip and no measureable change in dip between the two layers.

With greater velocity ratio $\left(\beta^{-1} \eta_{2} / \eta_{1}>2.1\right)$, but normalised migration speeds again small enough for the flow to be steady in the upper layer $\left(u_{\mathrm{m}} \eta_{1} / g\left(\rho_{\mathrm{s}}\right.\right.$ 
$\left.-\rho_{1}\right) \delta^{2}<0.12$ ), flow remained steady in the lower layer but the slab dip was smaller in the lower layer than in the upper layer (regime II). Both dips remained constant in time as the source traversed the length of the tank. The smaller dip in the denser and more viscous lower layer (Fig. 7b) is a result of a smaller sinking velocity there. In fact, the ratio $\tan \theta_{1} / \tan \theta_{2}$ increased linearly with increasing velocity ratio, a result consistent with (3). However, the angle change was slightly smaller than predicted and the data require a proportionality constant of 0.75 in the right-hand side of (3), most probably due to proximity of the tank base or three-dimensional deformation of the slab.

For normalised migration velocities greater than the critical value in the upper layer the slab dip in the lower layer was oscillatory while motion in the upper layer remained steady (regime III, Fig. 7c). This regime, however, was clearly observed in only one run (with a moderate value of $\nu_{1} / \nu_{2}$ ). The result is attributed to the narrow range of conditions that can lead to steady motion in one layer but oscillations in the other. It is also possible that stretching of the slab and curving of its edges while sinking in the upper layer, which maximises its dip, further limits the possibility of oscillations in the lower layer.

For normalised migration speeds less than 0.12 , but for large $\nu_{1} / \nu_{2}$, the slab did not pass directly through the interface but instead was laid down horizontally on the interface, where it remained for some time as a horizontal layer (regime IV) before slowly descending into the lower layer either as a long 'curtain' (Fig. 7d) or, at the largest $\nu_{1} / \nu_{2}$ $(\approx 80)$, as a chain of discrete diapirs. The structure was complicated by less dense upper layer material temporarily trapped beneath the horizontal part of the slab (not visible in Fig. 7d). The trapped upper layer material can later escape and so modifies the breakup and further sinking of the slab. The folding seen near the interface in experiments with stationary sources [44] again occurred but only in runs with the very largest sinking velocity ratio across the interface and small migration velocity. We have not subdivided regime IV accordingly.

At normalised migration velocities greater than the critical value $(0.12)$, the sheet descent was unsteady in the upper layer and therefore in the lower layer as well (regime V). The flow in the upper layer was oscillatory (as at large $u_{\mathrm{m}}$ in a single layer). Motion in the lower layer then took a different form, with large accumulations of slab material periodically impinging on the interface due to the upper layer instability and passing directly through the interface into the lower layer (with a reduction in sinking speed). This regime is illustrated in Figs. 7e and $\mathrm{f}$ for two experiments with different sinking velocity ratios. Within the range of conditions available to us the critical velocity was independent of the interface conditions, a result consistent with our observation that the unsteadiness involves an instability of the whole of the inclined slab and is not a result of interaction with the base of the tank or the interface. Hence the spacing of downwelling diapirs in the lower layer was determined entirely by the ratio of source migration speed and frequency of oscillation in the upper layer, and not at all by the properties of the interface or lower layer.

Finally, for values of $\beta<0$, for which the lower layer is more dense than the slab, we expect no permanent penetration of the interface and the flow in the upper layer will be similar to that in the single-layer experiments. Some temporary penetration may occur due to slab stiffness [43].

In summary, the data in Fig. 6 show that both the source migration velocity and the reduction in sinking velocity across the interface influence penetration of a dense slab into the lower layer. A decrease in the sinking velocity causes a decrease in the slab dip in the lower layer or the formation of a subhorizontal section of slab whose descent is delayed at the interface. This part of the slab may then be gravitationally unstable and descend into the lower layer as a 'curtain' or a chain of diapirs. If, on the other hand, the motion in the upper layer is unsteady, the slab material penetrates the interface as a chain of large diapirs whose spacing has nothing to do with the presence of the interface or lower layer properties.

\section{Discussion}

\subsection{Slab dip and trench migration}

Beyond identification of the various modes of slab behaviour the experiments can be used to pro- 

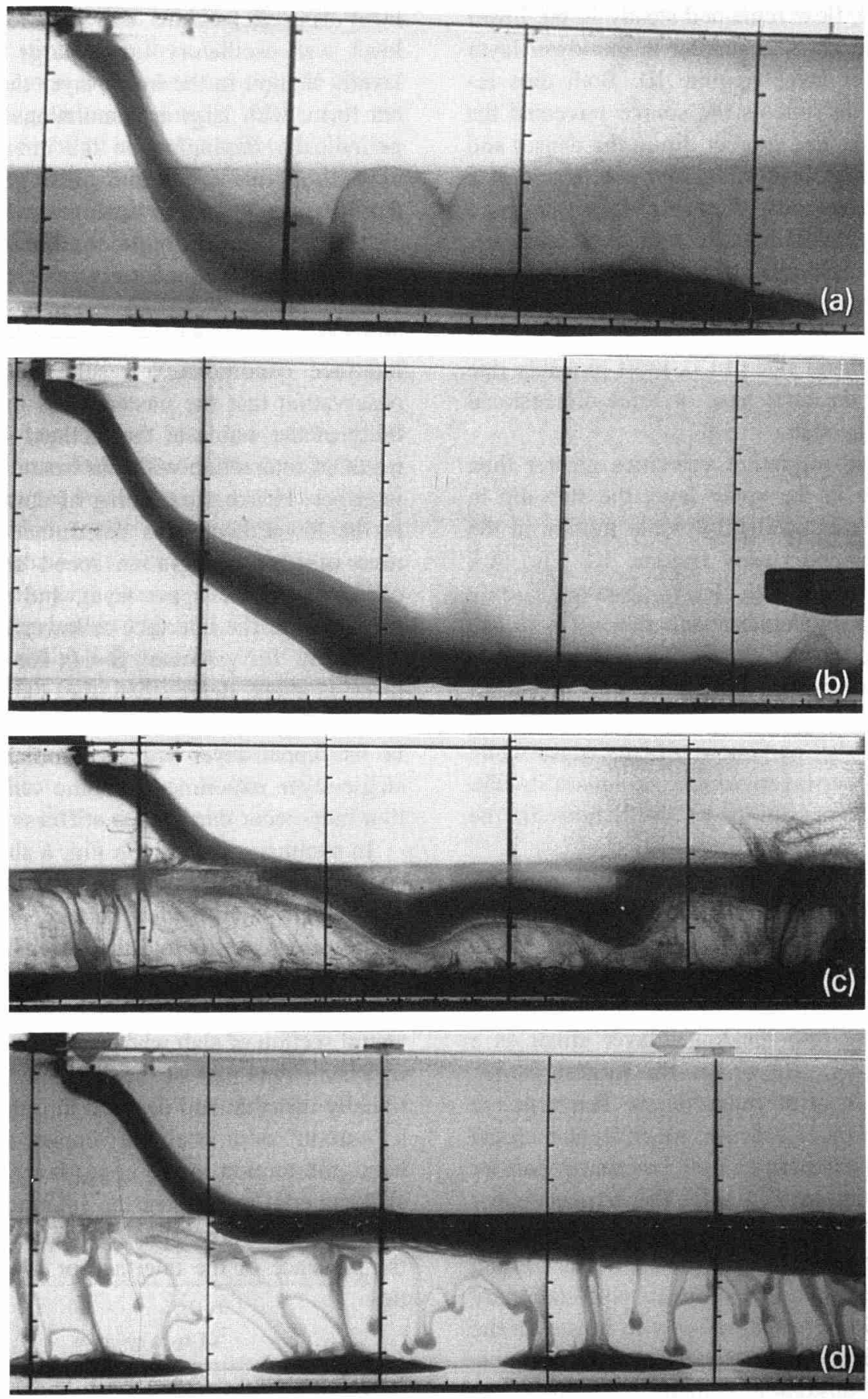

Fig. 7. Photographs illustrating slab morphology in the different flow regimes in Fig. 6 for two-layer experiments. (a) Regime I (run 9.1). (b) Regime II (run 12.3). (c) Regime III (run 8.2). (d) Regime IV (run 13.2). (e) Regime V with an interface giving a small velocity ratio $\nu_{1} / \nu_{2}$ (run 12.2). (f) Regime $\mathrm{V}$ with an interface giving a large ratio of sinking velocities (run 13.1). Experiment numbers refer to Table 1 . The last two photographs show cases in which the slab is oscillating in the upper layer and penetration of the interface is either immediate (e) or delayed (f). All of the dye visible below the slab in the bottom layer of (c) and (d) is a passive remnant of previous runs and does not influence the runs shown. Vertical scale marks are $2 \mathrm{~cm}$ and their horizontal spacing is $10 \mathrm{~cm}$. 

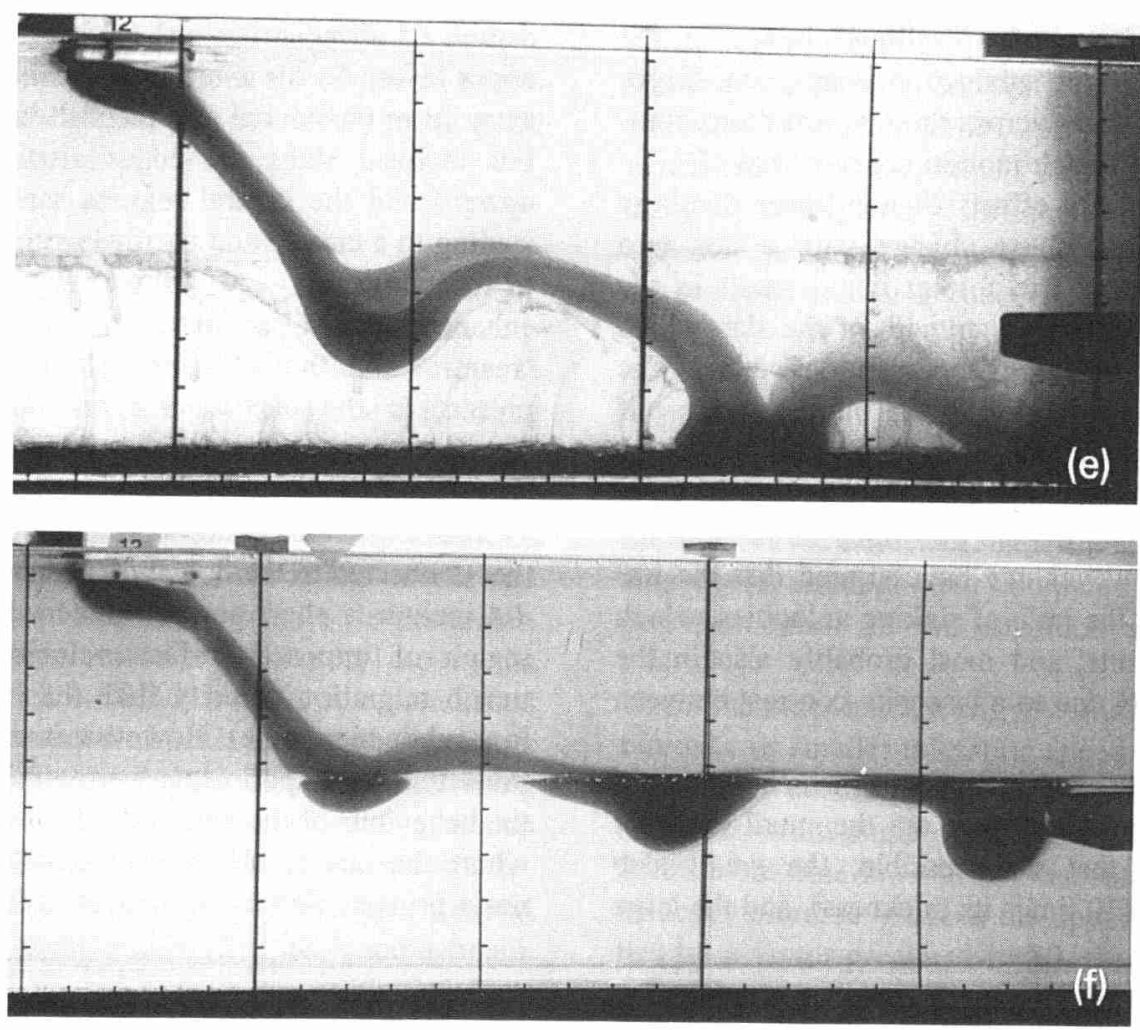

Fig. 7 (continued).

vide some quantitative insight into factors influencing the motion. In particular, the predicted simple relation between slab dip and trench migration can be tested and the proportionality constant $k$ evaluated. The measured dip (at mid-depth in the upper layer) shows a great deal of scatter when plotted against the normalised migration velocity (Fig. 8). However, as predicted, there is a trend to smaller dip for larger migration velocities and smaller sinking speeds. Much of the scatter may reflect a major difficulty encountered in measuring the slab thickness at mid-depth, and some may be a consequence of the flow not always reaching a steady state within the time taken for the source to traverse the length of the tank. The maximum and minimum dips in cases of oscillatory slab motion (again measured at middepth in the upper layer) straddle the mean dips for stable slabs extrapolated to smaller and unstable values of the normalised migration speed. A fit to the stable cases gives $k \approx 0.095 \pm 0.010$.

\subsection{Inadequacies of the experiments}

The experiments were designed to investigate the effects on descending slabs of a limited number of factors, namely trench migration and an increased resistance to motion or a reduced buoyancy force at an interface between two layers. We particularly do not aim to model the full complexity of the mantle but strive to simplify the problem, with a view to extracting the most essential aspects. Thus the experiments do not include many factors that may influence mantle convection and aspects of mantle flow other than that driven by the slab buoyancy. For 
example, the effects of upwelling plumes in the lower mantle, distant subduction zones, any largescale horizontal shear across the $660 \mathrm{~km}$ discontinuity and unsteady trench motion are removed.

Also removed are effects of non-linear rheology in the slab and a phase change with a non-zero Clapeyron slope $\gamma$. The former could result in the reduction of the effective strength of the slab which would enhance buckling and slab deflection. The latter provides a reduction in the buoyancy force if $\gamma<0$, albeit only in the near vicinity of the phase boundary, which can influence slab motion in ways similar to a change in slab buoyancy throughout the lower layer. However, we have argued that the important factor is the ratio of sinking velocities, which in the experiments, and most probably also in the mantle, is largely due to a viscosity contrast between layers.

Aspects of the experiments upon which we would have liked to have improved are the small range of slab 'stiffness' that is accessible, the small slab width (only 5 to 10 times its thickness), and the large degree of along-strike slab deformation within the upper layer. As the more viscous slab material sank away from the source slit, the slab width contracted. For inclined slabs the edges also tended to fold upward and the central regions sank more rapidly, leading to a curved and narrowing slab. Confinement of the buoyancy to a narrower slab will lead to an enhanced rate of penetration of both the upper layer 'mantle' and the interface. These effects may be present in the mantle, but are likely to be less significant because slabs are wider and may have greater resistance to deformation.

The experiments did not involve surface plates that connected to the downgoing slabs, although they did include a short perspex plate which provided a region of imposed surface velocity equal to the trench migration velocity (like the over-riding plate in a subduction zone). However, it should be kept in mind that the experiments were aimed at examining the behaviour of the viscous slab deep in the mantle, where the manner in which the slab is produced is not a primary factor. Perhaps of greater significance

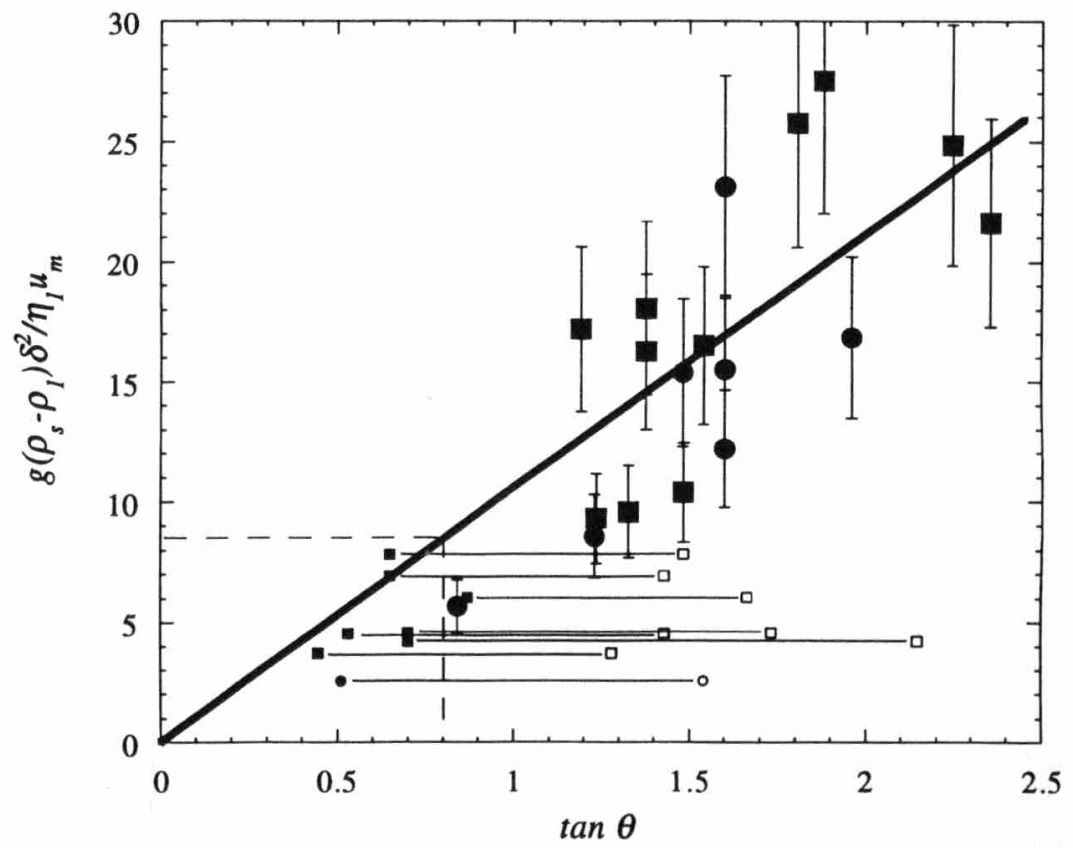

Fig. 8. The measured slab dip, expressed as $\tan \theta$, as a function of the normalised migration velocity. Large, filled symbols indicate runs with steady, stable slab descent in single-layer experiments $(-)$ and in the upper layer of two-layer experiments ( $\mathbf{m}$ ). Error bars show uncertainties resulting primarily from measurement of slab thickness. The trend is consistent with Eq. (3) and the line of best fit (to stable cases only) passing through the origin has a slope $k^{-1}=10.5$. For comparison minimum and maximum dip angles for cases with unsteady dip are shown (joined for each run). Also shown is the boundary to stable motion in the upper layer (broken lines, cf. Figs. 5 and 6 ). 
is that we imposed the trench migration velocity, whereas the interactions between slab rollback, trench migration and slab deflection are likely to be more complex in Earth.

\subsection{Application to Earth}

Most subduction systems on Earth are characterised by lateral migration of the trench that is accompanied by retrograde motion of the slab in the upper mantle [28,34]. Estimates of the relevant dimensionless parameters for Earth's mantle (Table 2) indicate that a number of the flow regimes identified in the laboratory might also occur in the mantle and lead to a variety of slab morphologies. In particular, the transition from stable to oscillatory dip in the upper layer, which is found to occur at a normalised trench migration speed of 0.12 , lies within the likely range of values for the mantle. For example, taking an upper mantle viscosity $\eta_{1} \approx 10^{21} \mathrm{~Pa} \mathrm{~s}$, a slab thickness $\delta \approx 100 \mathrm{~km}$, a temperature anomaly (averaged over the slab thickness) of $1000 \mathrm{~K}$, a thermal expansion coefficient of $3 \times 10^{-5} \mathrm{~K}^{-1}$ and a trench migration speed $u_{\mathrm{m}} \approx 3 \mathrm{~cm} / \mathrm{yr}$ toward the subducting plate, the normalised migration speed becomes $u_{\mathrm{m}} \eta_{1} / g\left(\rho_{\mathrm{s}}-\rho_{1}\right) \delta^{2} \approx 0.1$. This places the system on the transition between regime $\mathrm{V}$ (Fig. 6) and

\section{Table 2}

Parameter ranges for Earth and the experiments. Values for Earth are based on slabs with thickness $\delta=100 \mathrm{~km}$ falling through an upper mantle of uniform viscosity to the $660 \mathrm{~km}$ phase boundary, slab temperature anomalies of the order of $1000 \mathrm{~K}$, an upper mantle viscosity of $10^{20}-10^{21} \mathrm{~Pa} \mathrm{~s}$, trench migration speeds up to $7 \mathrm{~cm} / \mathrm{yr}[28,34]$, and evidence for a viscosity increase by a factor of $10-100$ at the phase boundary [15]

$\begin{array}{lll}\text { Parameter } & \text { Earth } & \text { Experiments } \\ H / \delta & \sim 7 & 5-10 \\ \eta_{s} / \eta_{1} & 10-100 & 6.5-8,400,2800 \\ \eta_{2} / \eta_{1} & 10-100 & 1.5-4.9,74,518 \\ \beta & \leq 1 & 0.18-0.75,1 \\ \beta^{-1} \eta_{2} / \eta_{1} & 10-100 & 2.0-30,80 \\ u_{m} \eta_{1} / g\left(\rho_{s^{-}} \rho_{1}\right) \delta^{2} & 0-2 & 0,0.1-0.22 \\ \theta \text { (from horizontal) } & 10^{\circ}-90^{\circ} & 30^{\circ}-70^{\circ}, 90^{\circ} \\ & & \end{array}$

either regime II or IV, the latter depending on the interface characteristics. For a larger upper mantle viscosity or greater trench speed application of the experimental results predicts that the slab dip will be unsteady and (given a sufficiently long history) the slab will penetrate through the transition zone into the lower mantle as a chain of large, spatially separated blobs. If the trench migration were a steadystate process, a snapshot would show regions of horizontal slab on the interface as well as regularly spaced masses sinking into the lower mantle. An unsteadiness of inclined slabs in the upper mantle is apparent in the numerical experiments of Gurnis and Hager [46], although their computations did not indicate penetration of the transition zone as discrete blobs.

On the other hand, a slightly smaller upper mantle viscosity or smaller migration speed than those taken above can, according to the experiments, lead to a stable, constant angle of dip in the upper mantle. If at the same time the $660 \mathrm{~km}$ discontinuity presents a viscosity increase between the upper and lower mantles by a factor greater than 30 , the ratio of sinking velocities $\nu_{1} / \nu_{2}=\beta^{-1} \eta_{2} / \eta_{1}>30$ (recall that $\beta<$ 1). Under these conditions the experiments predict a subhorizontal section of slab laid out on the viscosity interface, later to descend slowly into the lower mantle as either a chain of diapirs or as a long 'curtain' (regime IV). We suggest that diapirs would be the most likely form of motion in the lower mantle since lithospheric slabs tend to be much wider than the experimental slabs, which were strongly influenced by their finite width and were therefore more likely to form quasi-two-dimensional structures aligned with the direction of motion of the source. Also with $\nu_{1} / \nu_{2}>30$, folding of slabs before they are laid horizontally may be possible for small migration speeds. However, if the viscosity ratio $\eta_{2} / \eta_{1}<30$ it appears likely that only stationary and very slowly migrating trenches will admit steady-state slab-like penetration into the lower mantle (regime II). Since current information on mantle viscosity structure favours a viscosity increase by a factor of 10 to 100 between upper and lower mantles [15] it is not clear how often we can expect to observe continuous regions of high seismic velocity extending from the upper mantle to depths greater than $1000 \mathrm{~km}$. 
In principle the empirical value of the proportionality constant $k$ in the Stokes velocity scaling can be employed to compare the slab dips predicted by (3) with the dip of a number of deep Wadati-Benioff zones. However, many factors not included in the experiments, such as the present geometry of plate boundaries, spatial variations of plate and trench motions, the (varying) age of lithosphere at the trench, and the past history of plate and trench motions may all influence the shape of a subducted slab. It is also possible that, within the uncertainties shown in Fig. 8, $k$ may have a weak dependence on slab dip. Hence no straightforward collapse of observed slab dips of the form (3) should be expected.

Given the difficulties of reproducing in quantitative detail the conditions of subduction in the mantle, the most useful result of the experiments is the observation of a number of qualitatively different flow regimes, which may be of relevance to interpretation of seismic tomographic images. In particular the demonstration that dense slab material can be temporarily laid out at an interface before more slowly plunging through into a more viscous lower layer indicates that horizontal regions of high seismic velocity at the $660 \mathrm{~km}$ phase boundary do not imply that the boundary is a barrier to slab descent or that mantle motions are separated into two layers. The experiments show that slab morphologies similar to those inferred from tomography can be a result of added resistance to slab descent, and do not necessarily involve any reduction of the mass flux between layers.

The experimental results are particularly interesting when compared with the tomography of mature slabs below western Pacific island arcs [19-22]. For these subduction systems the rate of trench migration is often large (up to $70 \mathrm{~mm} / \mathrm{yr}$ for the Izu-Bonin trench [23] and between 30 and $55 \mathrm{~mm} / \mathrm{yr}$ for the Tonga and New Hebrides trenches [22,34]), and there is substantial along-strike variation in the migration rate. The rate and total amount of oceanward trench migration is approximately 3 times larger for the Izu-Bonin subduction zone than for the Mariana system further to the south. Images of the structure under the Izu-Bonin indicate slab accumulation at the base of the transition zone (Fig. 9). On the basis of the experimental results this lack of penetration is consistent with the rapid migration of the Izu-Bonin system during the period 30 to $17 \mathrm{Ma}$ (cf. Figs. $7 \mathrm{~b}$ and d). In the southwestern Pacific the slab of subducted Pacific plate is laid down in the transition zone between the upper and lower mantle below the

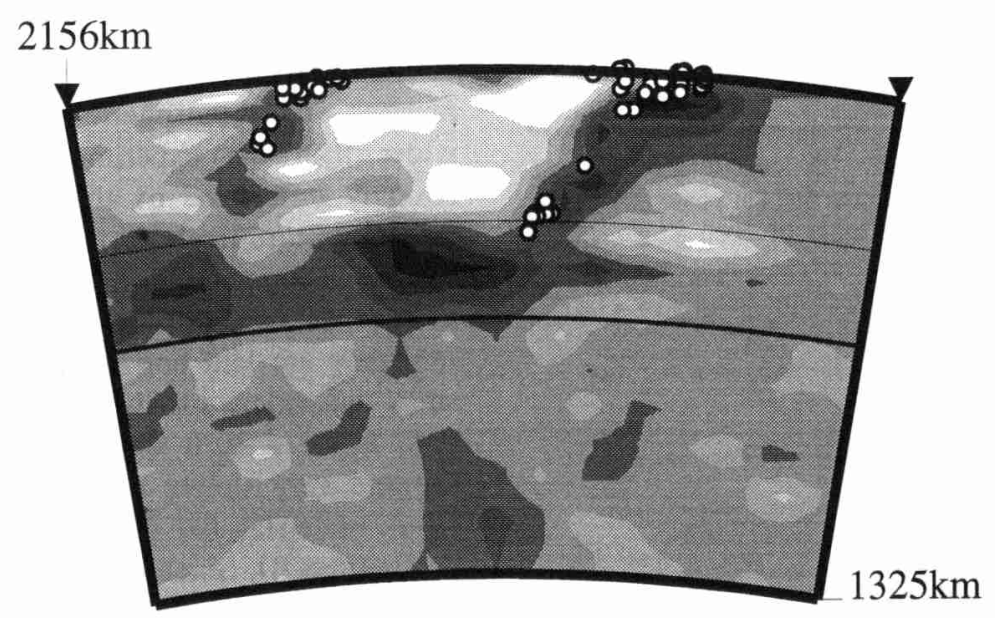

Fig. 9. Tomographic image of mantle structure beneath the northern part of the Philippine Sea plate (after [19,23]). The coordinates of the end points of the line of section are $\left(30.20^{\circ} \mathrm{N}, 125.09^{\circ} \mathrm{E}\right)$ and $\left(31.80^{\circ} \mathrm{N}, 147.86^{\circ} \mathrm{E}\right)$. The dark grey shading depicts faster than average P-wave propagation, which is associated with the subduction of the Pacific plate beneath the Izu-Bonin arc in the east and the Philippine Sea plate beneath the Ryukyu arc in the west. Light grey and white indicate relatively low P-wave speeds (e.g., below the volcanic arcs). In the upper mantle the blurred image of the slab is delineated by seismicity $(O)$. The heavy solid line depicts the $660 \mathrm{~km}$ discontinuity. The slab of subducted Pacific lithosphere is laid down in the transition zone beneath the northern part of the Philippine Sea plate [23]. 


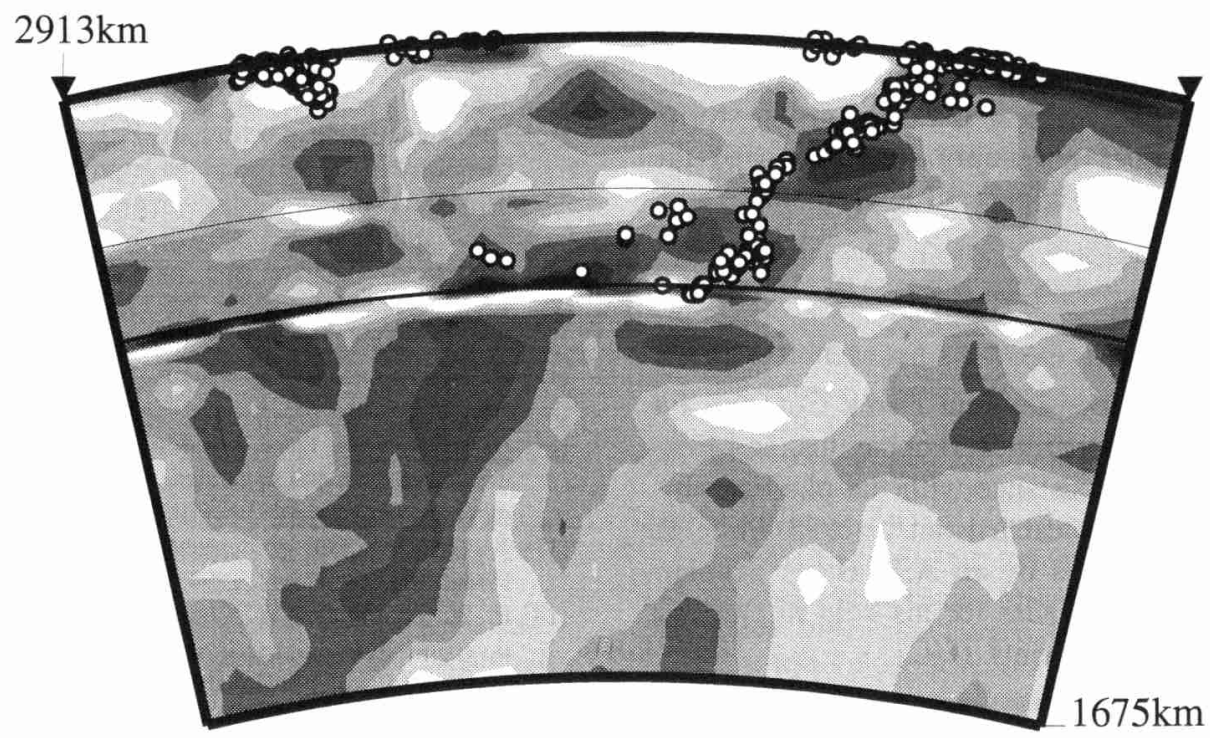

Fig. 10. Tomographic image of mantle structure beneath the northern part of the Tonga arc [22], from $\left(-23.25^{\circ} \mathrm{S}, 165.04^{\circ} \mathrm{E}\right)$ to $\left(-16.21^{\circ} \mathrm{S}, 167.75^{\circ} \mathrm{W}\right)$. For the explanation of the scale, see Fig. 9. The slab-like zone of high P-wave velocity beneath the Fiji basin is outlined by seismicity in the upper mantle and transition zone, but continues into the lower mantle without generating earthquakes. In the vicinity of the slab the image reveals low P-wave velocities between the 660 and $690 \mathrm{~km}$ depths, indicating a depression in the seismic discontinuity or phase boundary by $20-30 \mathrm{~km}$ relative to the depth in the reference earth model used.

Fiji basin (Fig. 10) but sinks into the lower mantle further to the west. The kink in the slab in the transition zone is again consistent with the fast lateral migration of the Tonga trench since the early Oligocene ( $\approx 35 \mathrm{Ma}$ ). On the other hand, slab penetration without interruption or kink in the transition zone is observed for the Mariana, northern Kuril and the Kermadec subduction systems, where the reported rates of trench migration are small $(<20$ $\mathrm{mm} / \mathrm{yr}$ ) [34]. This too is consistent with our observations of little interruption to slab descent for small migration velocities.

\section{Conclusions}

Experiment shows that slab behaviour in the upper mantle and transition zone may be related to the rate of trench migration relative to the sinking velocity of slabs in the upper mantle as well as to a reduction of sinking velocity as the slab encounters the lower mantle. This supports the observation of Van der Hilst et al. [19,20,22,23], based on seismic tomography and plate tectonic reconstructions, that the shape of the slab and the penetration through the $660 \mathrm{~km}$ phase boundary beneath the western Pacific island arcs is influenced by trench migration.

Our experimental results provide some quantification of the conditions under which various slab behaviours occur. Of particular significance in the slab deformation and style of penetration into the lower mantle is whether the slab descent within the upper mantle is steady or unsteady. If this descent is steady, the characteristics of the phase boundary further influence slab behaviour and morphology. The experiments indicate that slabs may be unsteady in the upper mantle for normalised trench migration speeds greater than a critical value, and that this critical speed is probably within the range of conditions encountered in Earth's mantle. For smaller migration speeds an interface causes marked deformation of slabs if the viscosity ratio (or density difference) between layers is not small. In additon (but not reported in detail here) unsteady motion of the surface plates or trench will strongly affect slab morphology and penetration style. Most subduction systems are characterized by significant rates of trench migration [34] and it is, therefore, likely that 
the impedance to slab descent offered by the $660 \mathrm{~km}$ discontinuity prevents many slabs from continuing into the lower mantle in a planar slab-like form. This, however, does not imply a reduction of the mass flux between the upper and lower mantle.

\section{Acknowledgements}

We thank Tony Beasley and Derek Corrigan for assistance with the experimental apparatus, and Ross Wylde-Browne for assistance with the photography. The experiments were carried out in 1993 while R. Hackney was supported by an A.L. Hales Scholarship, and we thank A. Kiss for his help in carrying out some of the experiments. $[\boldsymbol{U C}]$

\section{References}

[1] T.H. Jordan, Lithospheric slab penetration into the lower mantle beneath the Sea of Okhotsk, J. Geophys. Res. 43, 473-496, 1977

[2] K.C. Creager and T.H. Jordan, Slab penetration into the lower mantle, J. Geophys. Res. 89, 3031-3049, 1984

[3] K.C. Creager and T.H. Jordan, Slab penetration into the lower mantle below the Mariana and other island arcs of the northwest Pacific, J. Geophys. Res. 91, 3573-3589, 1986.

[4] P.G. Silver and W.W. Chan, Observations of body-wave multipathing from broadband seismograms: evidence for lower mantle slab penetration beneath the Sea of Okhotsk, J. Geophys. Res. 91, 13787-13802, 1986.

[5] T. Kamiya, K. Miyatake and K. Hirahara, How deep can we see the high velocity anomalies beneath the Japan island arcs?, Geophys. Res. Lett. 15, 828-831, 1988.

[6] K.M. Fischer, T.J. Jordan and K.C. Creager, Seismic constraints on the morphology of deep slabs, J. Geophys. Res. 93, 4773-4783, 1988.

[7] S.P. Grand, Tomographic inversion for shear velocity beneath the North American plate, J. Geophys. Res. 92, 14065-14090, 1987.

[8] S.P. Grand, Mantle shear structure beneath the Americas and surrounding oceans, J. Geophys. Res. 99, 11591-11622, 1994.

[9] M. Barazangi, B.L. Isacks, J. Oliver, J. Dubois and G. Pascal, Descent of lithosphere beneath New Hebrides, Tonga-Fiji and New Zealand, evidence for detached slabs, Nature 242, 98-101, 1973.

[10] D. Giardini and J.H. Woodhouse, Deep seismicity and models of deformation in Tonga subduction zone, Nature 307, 505-509, 1984.

[11] D. Giardini and J.H. Woodhouse, Horizontal shear flow in the mantle beneath the Tonga arc, Nature 319, 551-555, 1986.
[12] K. Okino, M. Ando, S. Kaneshima and K. Hirahara, A horizontally lying slab, Geophys. Res. Lett. 16, 1059-1063, 1989.

[13] P.B. Silver, W.W. Carlson and P. Olson, Deep slabs, geochemical heterogeneity and the large-scale structure of mantle convection: investigations of an enduring paradox, Annu. Rev. Earth Planet. Sci. 16, 477-541, 1988.

[14] P. Olson, P.G. Silver and W.W. Carlson, The large-scale structure of convection in the Earth's mantle, Nature 344, 209-215, 1990.

[15] G.F. Davies and M.A. Richards, Mantle convection, J. Geol. 100, 151-206, 1992.

[16] A.E. Ringwood, Phase transformations and their bearing on the constitution and dynamics of the mantle, Geochim. Cosmochim. Acta 55, 2083-2110, 1991.

[17] T. Lay, The fate of descending slabs, Annu. Rev. Earth Planet. Sci. 22, 33-61, 1994.

[18] H.-W. Zhou and R.W. Clayton, P and S wave travel-time inversions for subducting slab under the island arcs of the northwest Pacific, J. Geophys. Res. 95, 6829-6854, 1990.

[19] R.D. van der Hilst, E.R. Engdahl, W. Spakman and G. Nolet, Tomographic imaging of subducted lithosphere below northwest Pacific island arcs, Nature 353, 47-53, 1991.

[20] R.D. van der Hilst, E.R. Engdahl and W. Spakman, Tomographic inversion of $\mathrm{P}$ and $\mathrm{pP}$ data for aspherical structure below the northwest Pacific region, Geophys. J. Int. 115, 264-302, 1993.

[21] Y. Fukao, M. Obayashi, H. Inoue and M. Nenbai, Subducting slabs stagnant in the mantle transition zone, J. Geophys. Res. 97, 4809-4822, 1992.

[22] R.D. van der Hilst, Subducted lithosphere cascading into the lower mantle below Fiji-Tonga, Nature, in press, 1995.

[23] R.D. van der Hilst and S. Seno, Effects of relative plate motion on the deep structure and penetration depth of slabs below the Izu-Bonin and Mariana island arcs, Earth Planet. Sci. Lett. 120, 395-407, 1993.

[24] J. Oliver and B.L. Isacks, Deep earthquake zones, anomalous structures in the upper mantle, and lithosphere, J. Geophys. Res. 72, 4259-4275, 1967.

[25] B.L. Isacks, J. Oliver and L.R. Sykes, Seismology and the new global tectonics, J. Geophys. Res. 73, 5855-5899, 1986.

[26] S. Uyeda and H. Kanamori, Back-arc opening and mode of subduction, J. Geophys. Res. 84, 1049-1062, 1979.

[27] P.R. Lundgren and D. Giardini, Seismicity, shear-failure and modes of deformation in deep subduction zones, Phys. Earth Planet. Inter. 74, 63-74, 1992.

[28] R.D. Jarrard, Relations among subduction parameters, Rev. Geophys. 24, 217-284, 1986.

[29] P. Molnar and T. Atwater, Interarc spreading and cordilleran tectonics as alternates related to the age of subducted oceanic lithosphere, Earth Planet. Sci. Lett. 41, 330-340, 1978.

[30] N.J. Vlaar and M.J.R. Wortel, Lithospheric aging, instability, and subduction, Tectonophysics 32, 331-351, 1976.

[31] M.J.R. Wortel and N.J. Vlaar, Age-dependent subduction of oceanic lithosphere beneath western South America, Phys. Earth Planet. Inter. 17, 201-208, 1978.

[32] D.J. Stevenson and J.S. Turner, Angle of subduction, Nature 270, 334-336, 1977. 
[33] W.C. Tao and R.J. O'Connell, Ablative subduction: a twosided alternative to the conventional subduction model, J. Geophys. Res. 97, 8877-8904, 1992.

[34] Z. Garfunkel, C.A. Anderson and G. Schubert, Mantle circulation and the lateral migration of subducted slabs, J. Geophys. Res. 91, 7205-7223, 1986.

[35] U.R. Christensen and D.A. Yuen, The interaction of a subducting lithospheric slab with a chemical or phase boundary, J. Geophys. Res. 89, 4389-4402, 1984.

[36] U.R. Christensen and D.A. Yuen, Layered convection induced by phase transitions, J. Geophys. Res. 90, 1029110300, 1985.

[37] P. Machetel and P. Weber, Intermittent layered convection in a model mantle with an endothermic phase change at 670 $\mathrm{km}$, Nature 350, 55-57, 1991.

[38] R. Peltier and L.P. Solheim, Mantle phase transitions and layered chaotic convection, Geophys. Res. Lett. 19, 321-324, 1992.

[39] W. Zhao, D.A. Yuen and S. Honda, Multiple phase transitions and the style of mantle convection, Phys. Earth Planet. Inter. 72, 185-210, 1992.

[40] S.A. Weinstein, Catastrophic overturn of the Earth's mantle driven by multiple phase changes and internal heat generation, Geophys. Res. Lett. 20, 101-104, 1993.
[41] S. Honda, S. Balachander, D.A. Yuen and R. Reuteler, Three-dimensional mantle dynamics with an endothermic phase transition, Science 259, 1308-1311, 1993.

[42] P.J. Tackley, D.J. Stevenson, G.A. Glatzmaier and G. Schubert, Effects of an endothermic phase transition at $670 \mathrm{~km}$ depth on spherical mantle convection, Nature 361, 699-704, 1993.

[43] C. Kincaid and P. Olson, An experimental model of subduction and slab migration, J. Geophys. Res. 92, 13832-13840, 1987.

[44] R.W. Griffiths and J.S. Turner, Folding of viscous plumes impinging on a density or viscosity interface, Geophys. J. 95, 397-419, 1988.

[45] R.W. Griffiths and J.S. Turner, Viscous entrainment by sinking plumes, Earth Planet. Sci. Lett. 90, 467-477, 1988

[46] M. Gurnis and B. Hager, Controls on the structure of subducted slabs, Nature 335, 317-321, 1988.

[47] S. Zhong and M. Gurnis, Mantle convection with plates and mobile, faulted plate margins, Science, 1994.

[48] M.A. Richards and R.W. Griffiths, Deflection of plumes by mantle shear flow: experimental results and a simple theory, Geophys. J. 94, 367-376, 1988. 